\title{
POÉTICAS CONTEMPORÂNEAS
}

Poesia em revista: Oroboro

\section{Helena Alves Gouveia}

A serpente que engole a si mesma é uma figura curiosa do simbolismo de um processo de contínua transformação, de um movimento circular incessante, rumo à infinitude, sem traços de fim ou começo. Oroboro é um nome de origem grega que remete a esta serpente que se morde e penetra em si mesma ao engolir o próprio rabo. Mas também é o nome da revista de cultura editada em Curitiba pelos artistas-editores Ricardo Corona e Eliana Borges.

Segundo Maria Lucia de Barros Camargo, o século XX assistiu à propagação de uma série de revistas literárias e culturais, que quando analisadas e estudadas ajudam a pensar o perfil cultural da época à qual pertenceram. Ainda segundo a autora, as revistas do início do século $X X$ tiveram sua influência quando estruturaram o campo literário ao constituírem um meio singular da produção poética e de idéias e princípios estéticos de grupos que se organizavam em torno da própria revista. Estas, por sua vez, traçavam seu campo de atuação, o que muitas vezes causava a formação de um grupo literário. Estes grupos se organizavam em torno de determinada manifestação pública coletiva propalando manifestos, palavras de ordem e novidades criativas. Dessa forma, as revistas literárias e culturais tinham, entre outras, a função de criar uma identidade e um grupo literário que se reunisse em torno delas. Entretanto muitas dessas publicações foram se encerrando, e entre alguns dos motivos podem-se destacar as dificuldades financeiras, uma vez que se tratavam de revistas independentes, além do fato de que seus realizadores, num determinado momento, puderam contar com outras vias, essas já institucionalizadas, para a difusão de suas idéias. M. Lucia B. C. ainda observou que os periódicos literários e culturais surgiram em momentos de fortes desejos por uma renovação estética, em que novas propostas necessitavam ser veiculadas.

Assim, pela inexistência atual de uma vanguarda ou de grupos antagônicos, parece que não haveria mais espaço para revistas literárias de 
formação cultural independente. Contudo estas revistas ressurgiram, no final do século $X X$, num contexto muito diferente, ou seja, diante de um pluralismo que permite que todos os movimentos ou formas de pensamentos tenham seu espaço sem a necessidade de disputas. Dessa forma, as revistas literárias reapareceram a partir deste recente final de século, em que os espaços dedicados à poesia não só voltaram a existir, mas são bastante amplos ${ }^{1}$.

É nesse contexto que se insere a Oroboro, Revista de Poesia e Arte, publicada já no início do século XXI, não de forma independente, como era comum no início do século passado, mas com o incentivo financeiro governamental, por meio do benefício da Lei Municipal de Incentivo à Cultura, que contemplou oito edições, publicadas pela Editora Medusa, entre setembro de 2004 e agosto de 2006.

E talvez por este incentivo ser limitado, a revista já tenha nascido com seu fim previsto, pensado e projetado para a oitava edição. Essa finitude dos oito números, contudo, pode ser repensada quando se percebe que o número oito, quando deitado, permite ser visto como o símbolo do infinito, o que remete, de alguma forma, ao sugerido pela serpente que engole o próprio rabo.

Augusto de Campos ${ }^{2}$ afirma que, na simbologia de Paul Valéry, a serpente seria o "ícone do pensar", atividade que Valéry teria levado ao limite de poder afirmar: "Eu 'contenho' o que me 'contém'. E sou sucessivamente continente e conteúdo", o que para Augusto de Campos representaria "impotência e infinito".

Na capa de cada uma das edições da revista, no canto superior direito, cuja borda é arredondada, aparecem os números de um a oito seguindo dita curva. O número respectivo a cada edição é destacado, sendo maior e de outra cor. Assim aparece o número oito, deitado, na capa de todas as edições de Oroboro, podendo indicar uma possível infinitude.

Este estudo pretende discutir, pela análise do periódico em questão, o caminho que segue a poesia e as outras formas de arte no final do século $X X$

\footnotetext{
${ }^{1}$ CAMARGO, Maria Lucia de Barros. "Plvs élire que lire" A poesia e suas revistas no final do século $X X$. In: do presente. Chapecó: Argos, 2001.

${ }^{2}$ CAMPOS, Augusto de. Paul Valéry: a serpente e o pensar. São Paulo: Brasiliense, 1984.
} 
no começo do século XXI: as formas de organização dos artistas e das revistas num tempo em que não há mais a necessidade de disputas para se obter um espaço, institucionalizado ou não, para a articulação de um determinado pensamento.

Oroboro, Revista de Poesia e Arte, conta, em seu corpo editorial ${ }^{3}$, com treze nomes, entre eles um argentino e um estadunidense ${ }^{4}$. As edições foram trimestrais e têm aproximadamente 50 páginas, numeradas no rodapé. A tiragem não é informada na revista, mas sua distribuição, realizada pela Editora lluminuras, foi nacional e feita somente em livrarias, o que pode traçar um perfil de seu público-alvo, formado por universitários, freqüentadores de livrarias, e por artistas ligados à literatura e às artes visuais.

Ao se abrir a revista, não se vêem editorial, textos críticos nem publicidade. Seus espaços são totalmente dedicados à literatura e às artes visuais, estabelecendo uma ligação muito estreita entre estas expressões e as apresentações e entrevistas, realizadas pelos membros do corpo editorial, aos artistas escolhidos.

Há, entretanto, a escolha clara por um determinado projeto gráfico e por um elenco de colaboradores que suprime limites regionais e formais. Ainda que patrocinada pelo Estado, não há exclusividade a editores, colaboradores e autores paranaenses, tampouco brasileiros ou sul-americanos, uma vez que, como dito anteriormente, e talvez seja válido destacar, Oroboro foi editada em Curitiba.

O projeto gráfico da Oroboro, realizado pela artista plástica e editora Eliana Borges, não é comum ao de outras revistas de poesia, que freqüentemente têm cara de livro. Oroboro tem o miolo preto e branco e capas coloridas, exceção feita à edição número cinco, que tem a capa em tons de cinza. O tamanho do papel, de 23 por 28 centímetros, e o recorte da revista já marcam uma clara diferença em relação a outros periódicos de poesia. Além

\footnotetext{
${ }^{3}$ Os membros do conselho editorial são, em ordem alfabética: Antonio Cicero (RJ), Charles A. Perrone (EUA), Eduardo Kak (EUA), Flávia Rocha (PR), Isabel de Castro (RS), Joca Wolff (SC), Key Imaguire Jr. (PR), Marcelo Sandmann (PR), Mário Câmara (Argentina), Manoel Ricardo de Lima (CE), Ricardo Aleixo (MG), Ricardo Lísias (SP) e Rubens Pileggi Sá (PR).

${ }^{4}$ Eduardo Kak é brasileiro, mas na ficha que consta no final da revista, tem a sigla dos estados unidos após seu nome. Da mesma forma, Manoel Ricardo de Lima, piauiense, atualmente residindo em Florianópolis, leva atrás de seu nome a silga do Ceará. Talvez estas identificações correspondam ao local onde os colaboradores se encontravam no momento da edição da revista.
} 
disso, entre as seções internas encontram-se textos e artes gráficas em fundo branco, cujos títulos se confundem com eles próprios, e não há marcações claras de limites entre as "seções" ${ }^{5}$ ou poemas e intervenções. Muitas vezes não há sequer título, apenas o nome do autor, confundindo-se, por vezes, ao corpo da obra.

A organização interna da revista segue, na maioria dos números, um padrão determinado, mas que só pode ser percebido na observação de mais de um número, pois as seções, com exceção de Orobário e (c)obra, não são nomeadas: no início da revista, ocupando geralmente o lugar das primeiras seções, têm-se o que chamarei aqui de dossiê sobre algum artista, contendo uma mostra de seu trabalho. A palavra "dossiê" não é a utilizada na revista, mas será aqui por uma necessidade de nomeação e por se tratar do registro de informações a respeito de um artista, e que vai além de uma simples apresentação, reunindo, além de uma mostra de seu trabalho, um ensaio sobre sua produção e uma entrevista.

A quase ausência de classificação e de divisão entre as seções da revista se estende às manifestações artísticas publicadas, que muitas vezes não se encaixam nas categorias de poemas ou de artes plásticas: apresentamse mais como uma mescla dessas expressões, o que traz, inclusive, uma dificuldade no momento da indexação segundo a metodologia proposta para a utilização da base de dados para os projetos do Nelic. Além disso, os artistas publicados na revista na maioria das vezes também não se encaixam nas definições mais comuns existentes, podendo ser chamados de "multiartistas", que é a forma como o editor Ricardo Corona designa, por exemplo, o "poeta, performer e artista gráfico" Edwin Torres, no dossiê do primeiro número de Oroboro.

Os artistas escolhidos para a realização dos dossiês foram o performer e artista gráfico estadunidense Edwin Torres, apresentado e entrevistado por Ricardo Corona; a artista plástica, professora e pesquisadora gaúcha Elida Tessler, apresentada e entrevistada por Manoel Ricardo de Lima; a escritora carioca Claudia Roquette-Pinto, apresentada e entrevistada por Marcelo

\footnotetext{
${ }^{5}$ Chamarei as partes que compõem a revista de "seções", embora este não seja o melhor termo, uma vez que remete a algo seccionado, dividido, quando a revista se caracteriza fortemente pela ausência de limites e divisões.
} 
Sandmann; o poeta e tradutor argentino Arturo Carrera, apresentado por Joca Wolff e entrevistado por Nancy Fernández; o poeta, músico, produtor cultural e artista plástico mineiro Ricardo Aleixo, apresentado e entrevistado por Ricardo Corona. A sexta edição é a única a não conter a seção de dossiê e entrevista. A sétima traz o cartunista e poeta paulista Luiz Antonio Solda, apresentado e entrevistado por Key Imaguire Jr, e a oitava, o escritor mineiro Evandro Affonso Ferreira, apresentado e entrevistado por Júlia Studart.

A poesia do estadunidense Edwin Torres utiliza expressões vocais e neologismos no que Ricardo Corona chama de "estilo jamaicano", com vocábulos latinos incorporados, cujos sons vocálicos, ritmo e lirismos agradam o poeta, que se revelou, dessa forma, um artista experimental. Em 1991 realizou sua primeira publicação de livro, com um projeto gráfico com diagramação entremeada de grafites, manchas gráficas, linhas, setas, desenhos geométricos, diferentes fontes e tamanhos de corpo de texto. A veiculação de sua poesia, entretanto, não se restringe ao papel: a poesia gravada em CD explora, por exemplo, a maneira como o som pode existir na linguagem poética.

A gaúcha Elida Tessler, além de artista plástica, é professora do Programa de Pós-Graduação em Poéticas Visuais da UFRGS e coordena um espaço não institucional para experimentação em arte contemporânea, que também funciona como atelier e sala de aula. Seus projetos e exposições, como Manicure, em que dezenas de vidros de esmalte seco estão dispersos sobre uma mesa, Claviculário e Todos os Nomes Chaves, que reúnem centenas de chaves, por exemplo, exploram objetos prontos, numa espécie de ready made, cujo amontoamento ou coleção sistemática cria a idéia de certo tipo de ordenação que, segundo a autora, pretende despertar no espectador alguma vertigem.

O primeiro livro do poeta mineiro Ricardo Aleixo, publicado em 1992, em que não utilizou o verso alinhado, foi rotulado pela crítica de pós-concretista. Ricardo está envolvido, além da poesia, em atividades artísticas como a música, a poesia sonora, as artes plásticas, a crítica e a performance. A qualificação de multiartista, dada por Ricardo Corona a Edwin Torres, parece se encaixar também no perfil de Ricardo Aleixo. Neste dossiê, entretanto, o 
prefixo multi- aparece na palavra "multicontexto", que Corona explica como sendo o que "aproxima o antigo e o moderno, a escrita e a oralidade, o livro e o CD." Tendo, dessa forma, a experiência com a linguagem como uma conseqüência dessas aproximações.

A seção (c)obra é destacada por um recorte na lateral da página e geralmente apresenta um escritor e alguns de seus textos ou fragmentos deles. Em cada uma das oito edições, essas páginas foram dedicadas aos trabalhos do poeta uruguaio Víctor Sosa, apresentado por Cláudio Daniel; do escritor paulista Valêncio Xavier; do poeta, crítico literário e artista plástico francês Pierre Reverdy, apresentado por Júlio Castañon Guimarães e Ronald Polito; da poeta, tradutora, colunista e editora polonesa Wislawa Szymborska, apresentada por Regina Przybycien; do escritor Jean Joseph Rabearivelo, nascido em Madagascar, apresentado por Antônio Moura; do desenhista, pintor, escritor e poeta inglês Edward Lear, apresentado por Dirce Waltrick do Amarante; do escritor paranaense Wilson Bueno e, finalmente, do poeta também paranaense Sérgio Rubens Sóssela, apresentado por Ademir Demarchi.

O curitibano Sérgio Rubens Sóssela foi juiz por profissão, mas nunca se interessou por essa carreira. Preferiu ser escritor e construir uma biblioteca anexa à sua casa, onde passava a maior parte do dia isolado. Concebeu artesanalmente e tornou públicos 10 a 20 exemplares de mais de 300 títulos, que enviava a poucos amigos. O apresentador da seção, Ademir Demarchi, vê sua obra como caracterizada pela fragmentação, sendo a chave para sua compreensão o fato de que "o todo somente pode ser visto ou compreendido a partir de uma soma de fragmentos.." ${ }^{6}$ É interessante notar sua múltipla relação com o livro: concebê-los artesanalmente, após escrever os textos, e distribuílos aos amigos traça uma convivência intensa do autor com seu livro e com a literatura, que passa a não ter, por sua vez, vínculo com o mercado, com as instituições e nem com a massa, formando uma ligação íntima com os leitores e mais ainda com o autor. Não há, nesse caso, patrono, nas formas como descreve Raymond Williams (2000), mas há público. Esse público, entretanto, não está ligado ao mercado, pois essas obras não estão à venda. Sóssela,

\footnotetext{
${ }^{6}$ Oroboro, revista de poesia e arte. $n^{\circ}$ 08. Curitiba: Medusa: jun/jul/ago de 2006. p. 24.
} 
portanto, se vê de fora das relações de mercado e participa de todas as etapas da produção e da distribuição de seus livros, o que permite uma extrema liberdade de criação, ainda que o mercado atual abrigue uma variedade tão grande de manifestações.

Pode-se dizer que a (c)obra também compõe um dossiê, por apresentar muitas vezes um texto sobre determinado autor e uma mostra de sua obra, o que o documenta e o dá a conhecer. Percebe-se que a maioria dos artistas escolhidos para compor essas duas importantes seções da revista acumula habilidades e atividades artísticas. Um poeta também ocupa o lugar da crítica, ou organiza e publica sua própria produção; um desenhista também se considera poeta, quando pensa o cartum como poesia sem palavras; uma professora e pesquisadora, que atua numa instituição acadêmica, também atua como artista plástica; um poeta se transforma num performer e não restringe sua poesia à folha de papel, mas a leva ao palco e ao CD. É muito marcante essa frouxidão das separações entre o que é poesia e música, artes plásticas e poesia, por exemplo, ou entre as funções e os lugares em que esses artistas atuam, numa multiplicidade comum aos tempos atuais.

A penúltima seção da revista se chama "Orobário". Em cada edição é publicado um poema, em prosa ou em verso, de diferentes escritores, com um tema que discute os mitos de medusa e oroboro. Na primeira edição, Ricardo Corona abre esta seção escrevendo "s(c)obra", cujos versos, assimétricos, se apresentam imitando a forma de uma serpente. O título se desdobra em três palavras: obra, sobra e cobra, que compõem três versos: "sou obra do cabelo da outra", "sou sobra do cabelo da outra", "sou cobra do cabelo da outra", evocando o mito de medusa. Na segunda, Wagner Mangueira apresenta seu poema em prosa "Contorcível". Depois, "Soneto 1001 rodador", de Glauco Mattoso. A quarta edição conta com "Vamos comer o próprio rabo", poema em prosa de Carlos Careqa. Na quinta edição, Dennis Radünz mostra sua "Última epístola ao império", e na sexta, tem-se "Tempo impotente", de Augusto de Campos, escrito em 1957. Na penúltima edição, lê-se "Oroboro dois", poema em prosa de Celso Borges. Finalmente, o último número mostra um poema sem título de Carlos Augusto de Lima, com seu nome inserido numa das bolas 
do número oito, que, acompanhando a palavra Orobário, remete ao símbolo do infinito, por ser lido deitado.

A última seção da revista, na última página e no verso da contra-capa, é sempre composta de quadrinhos. Da primeira à última edição se vêem: "Pai", um "delírio" de Maxx Figueiredo; "Up Frogs", de Mauricio Benega; "Litoarrostema Normando", de Píer Paolo; "Olivieri, Albartoz", de Simon Luis Ducroquet; "Quadrinhofilia", de José Aguiar, seguido de um texto de sua autoria; um quadrinho sem título de Lupin + Cioran; "Paradox Murder", de Antonio Eder; e, finalmente, "Redondinhos em quadrinhos", de Key Imaguire Jr.

Os temas das capas são, do primeiro ao oitavo número: um céu com nuvens claras e escuras; uma reprodução de grafites feitos em muro; uma rosa vermelha e um lagarto; duas bonecas de cerâmica, vistas de frente na capa e de costas na contra-capa; teclas de uma antiga máquina de datilografar, sendo esta a única capa feita em tons de cinza; fitinhas do Nosso Senhor do Bonfim; um inseto sobre uma folha verde de planta; um hipopótamo.

Penso as capas de Oroboro não como uma mostra direta do que será visto no interior da revista, mas como mais uma seção. Elas podem ser vistas como mais uma manifestação visual e poética, assim como as que aparecem no corpo da revista.

As nuvens da primeira capa mostram formas possíveis, livres, cambiantes, assim como as formas contemporâneas de arte e do fazer artístico. É possível pensar a mudança na coloração das nuvens, que pode anunciar uma mudança no tempo, no clima, como uma mudança nas formas da arte e do fazer poético e artístico que tanto mudou com o passar do tempo, ora com o predomínio das formas, ora com o predomínio do conteúdo, algumas vezes fazendo parte do esquema institucional, outras de forma marginal, ora leve e clara, ora carregada e obscura.

A capa da segunda edição mostra um muro ilustrado de grafite, uma forma de pintura marginal, característica e predominante nas grandes cidades. A terceira capa de Oroboro ilustra uma rosa vermelha e uma argola de ferro. Uma forma delicada e efêmera é contrastada a uma forma bruta, grosseira, enferrujada, mas fixa e permanente. Assim podem ser pensadas as criações artísticas que, por mais que se achem inovadoras ou originais, ainda se apóiam 
em formas e estruturas velhas que, ainda que enferrujadas e ultrapassadas, podem servir, senão de base para uma invenção, pelo menos como forma a ser desconstruída.

As bonecas de cerâmica da revista número quatro são as típicas do artesanato regional mineiro. Podem ser encontradas, entretanto, em feiras de artesanato em diversas partes do Brasil, até mesmo em shoppings e em lojas de decoração. Assim, pode-se pensar a quebra de fronteiras regionais existente, por exemplo, em Oroboro, ao juntar as produções de artistas de diversas regiões do país e de fora do país, e na quebra de fronteiras entre os gêneros artísticos e entre as seções da revista. As bonecas de cerâmicas estão em Minas ao mesmo tempo que estão no Amazonas ou na Bahia, compondo um afrouxamento das fronteiras.

A quinta capa de Oroboro é a única sem cores e mostra as teclas de uma máquina de escrever. $A$ imagem da máquina remete à idéia de progresso e de produção em série, de produção e reprodução, que faz pensar nas formas de arte vigentes na era da reprodutibilidade técnica descrita por Benjamin ${ }^{7}$. Segundo o autor, no século $\mathrm{XX}$ as técnicas reprodutivas teriam atingido o nível de poderem ser aplicáveis a todas as obras de arte do passado, modificando, com isso, suas formas de influência e se impondo, nessa condição, como formas originais de arte, o que mudou os valores do original e da reprodução, gerando um questionamento sobre a aura do objeto único confrontada com os valores impostos pelo mercado.

A sexta edição da revista traz na capa a ilustração de fitinhas do Senhor do Bonfim, padroeiro do estado brasileiro da Bahia, que na devoção católica é uma figuração de Jesus Cristo, venerado na visão de sua morte. A fitinha do Bonfim é originalmente um amuleto que se tornou o souvenir típico da capital baiana. Foi criada em 1809, conhecida como medida do Bonfim: media 47 centímetros de comprimento, a medida do braço direito da estátua de Jesus Cristo, Senhor do Bonfim, postada no altar-mor da igreja mais famosa da Bahia. Funcionava como uma moeda de troca: ao pagar uma promessa, o fiel carregava uma foto ou uma pequena escultura de cera representando a parte

${ }^{7}$ BENJAMIN, Walter. A obra de arte na era de sua reprodutibilidade técnica. In: Magia e técnica, arte e política: ensaios sobre literatura e história da cultura. São Paulo: Brasiliense, 1994. 
do corpo curada com o auxílio do santo (ex-voto). Como lembrança, adquiria uma dessas fitas, simbolizando a própria igreja.

As folhas comidas da capa número sete dão uma idéia de narrativa esburacada, em que o mais importante estaria em sua face oculta. Antoine Compagnon sugere que

"[...] deveríamos fazer uma história paradoxal da tradição moderna, concebida como uma narrativa esburacada, uma crônica intermitente. Possivelmente a face oculta de cada modernidade seja justamente a mais importante: as aporias e as antinomias extraídas das narrativas ortodoxas." 8

A oitava capa mostra o olhar fixo de um hipopótamo, um mamífero anfíbio, herbívoro, porém canibal, grande e agressivo, que contudo não possui predador natural. Seu perigo, dessa forma, reside em sua própria espécie. A arte e a poesia contemporâneas podem ser pensadas como paradoxais, anfíbias, canibais, quando fazem conviver manifestações tão distintas.

Uma das características marcantes de Oroboro é a sua escolha por aritstas "multi", ou multiartistas, para utilizar a definição do editor Ricardo Corona. Parece haver um enfraquecimento das especializações quando se observa o freqüente e numeroso aparecimento de artistas com mais de uma habilidade. Talvez caiba aqui a comparação com objetos frutos das tecnologias mais recentes, também multifuncionais: os celulares com câmera fotográfica, rádio, agenda, calculadora, etc, e as impressoras que também são copiadoras e scanners são alguns dos exemplos mais cotidianos que podem confirmar uma tendência atual às múltiplas funções encontradas num mesmo corpo. (juntar com o parágrafo do Benjamin??)

Não pode ser negada também uma disposição à experimentação por parte dos artistas presentes em Oroboro. Edwin Torres, Elida Tessler, Víctor Sossa são alguns dos artistas que se consideram experimentais. Além desse

${ }^{8}$ COMPAGNON, Antoine. Os cinco paradoxos da modernidade. Trad.: Cleonice Mourão, Consuelo Santiago, Eunice Galéry. Belo Horizonte: UFMG, 1996. p. 12. 
caráter, um aspecto freqüente observado nas páginas de Oroboro é a diversidade de possibilidades de veiculação da arte. A poesia sai dos limites do livro e vai até o palco ou até o CD. Os livros não são necessariamente organizados por uma editora e comercializados pelas livrarias, mas podem ser concebidos artesanalmente e distribuídos pelo próprio escritor; o cartum, por sua vez, leva à reflexão e faz poesia sem palavras.

A relação da poesia com a crítica também é tema das discussões de Oroboro. Enquanto alguns artistas, como é o caso de Arturo Carrera, conseguem ver a crítica como responsável por novas percepções, outros a enxergam negativamente, como criadora de rótulos, nem sempre bem aceitos.

A ausência de editorial e de ensaios ou textos críticos sobre a situação da poesia e da arte contemporânea que busquem criar panoramas ou diagnósticos pode ser um sintoma da natureza, de certa forma institucional, da revista, criada, como mencionado anteriormente, com recursos governamentais.

Raymond Williams $^{9}$ marca a importância de três tipos de instituições classificadas por ele como de "pós-mercado", por estarem inseridas numa organização social em que o mercado exerce importante papel. São elas: a instituição patronal moderna, que mantém determinados tipos de arte que não sejam lucrativas nem viáveis; a patronal governamental, que funciona como um departamento do Estado; e a instituição patronal intermediária, situada entre as duas citadas, que depende de recursos públicos, mas que dirige sua própria produção. Assim poderia ser pensada a Revista Oroboro, patrocinada pelo Estado, mas com seus próprios organizadores. Esse vínculo estatal pode, entretanto, ser determinante de uma atitude não-militante da revista, que não pretende lançar manifestos, subverter regras ou proferir explícitas opiniões em relação às formas de arte e cultura vigentes.

Essa ausência de manifesto em Oroboro também pode ser explicada pelo contexto plural do fim do século $X X$ e início do $X X I$, em que há espaço para todos os movimentos e formas de pensamento, como assinala Maria

\footnotetext{
${ }^{9}$ WILLIAMS, Raymond. Cultura. Trad.: Lólio Lourenço de Oliveira. São Paulo: Paz e Terra, 2000.
} 
Lucia de Barros Camargo $^{10}$. Dessa forma, não seriam necessárias grandes manifestações ou defesas de um certo tipo de pensamento num tempo em que há espaço para todos, sem disputas.

${ }^{10}$ CAMARGO, Maria Lucia de Barros. "Plvs élire que lire" A poesia e suas revistas no final do século XX. In:_ e PEDROSA, Célia (orgs.). Poesia e contemporaneidade: leituras do presente. Chapecó: Argos, 2001. 


\section{REFERÊNCIAS}

BENJAMIN, Walter. Magia e técnica, arte e política: ensaios sobre literatura e história da cultura. São Paulo: Brasiliense, 1994.

CAMPOS, Augusto de. Paul Valéry: a serpente e o pensar. São Paulo: Brasiliense, 1984.

CAMARGO, e PEDROSA, Célia (orgs.). Poesia e contemporaneidade: leituras do presente. Chapecó: Argos, 2001.

COMPAGNON, Antoine. Os cinco paradoxos da modernidade. Trad.: Cleonice Mourão, Consuelo Santiago, Eunice Galéry. Belo Horizonte: UFMG, 1996.

Oroboro, revista de poesia e arte. n 01. Curitiba: Medusa: set/out/nov de 2004.

. nº2. Curitiba: Medusa: dez/jan/fev de 2004/2005.

. n 03. Curitiba: Medusa: mar/abr/mai de 2005.

. n 04. Curitiba: Medusa: jun/jul/ago de 2005.

. $n^{\circ}$ 05. Curitiba: Medusa: set/out/nov de 2005.

. n 06. Curitiba: Medusa: dez/jan/fev de 2005/2006.

. n 07. Curitiba: Medusa: mar/abr/mai de 2006.

. n 08. Curitiba: Medusa: jun/jul/ago de 2006.

WILLIAMS, Raymond. Cultura. Trad.: Lólio Lourenço de Oliveira. São Paulo: Paz e Terra, 2000. 